\title{
Restructuring of lipid membranes by an arginine-capped peptide bolaamphiphile
}

Article

Accepted Version

Castelletto, V., Barnes, R. H., Karatzas, K.-A., Edwards-Gayle, C. J. C., Greco, F., Hamley, I. W. ORCID:

https://orcid.org/0000-0002-4549-0926, Seitsonen, J. and Ruokolainen, J. (2019) Restructuring of lipid membranes by an arginine-capped peptide bolaamphiphile. Langmuir, 35 (5). pp. 1302-1311. ISSN 0743-7463 doi:

https://doi.org/10.1021/acs.langmuir.8b01014 Available at https://centaur.reading.ac.uk/78789/

It is advisable to refer to the publisher's version if you intend to cite from the work. See Guidance on citing.

To link to this article DOI: http://dx.doi.org/10.1021/acs.langmuir.8b01014 Publisher: American Chemical Society

All outputs in CentAUR are protected by Intellectual Property Rights law, including copyright law. Copyright and IPR is retained by the creators or other copyright holders. Terms and conditions for use of this material are defined in the End User Agreement. 


\section{CentAUR}

Central Archive at the University of Reading

Reading's research outputs online 


\section{Restructuring of Lipid Membranes by an Arginine-Capped Peptide Bolaamphiphile}

Valeria Castelletto, ${ }^{\S, *}$ Ruth H. Barnes,,$^{\S}$ Kimon-Andreas Karatzas, ${ }^{\S}$ Charlotte J. C. EdwardsGayle, ${ }^{\S}$ Francesca Greco, ${ }^{\S}$ Ian W. Hamley, ${ }^{\S}$ Jani Seitsonen ${ }^{\ddagger}$ and Janne Ruokolainen ${ }^{\ddagger}$

$\S$ School of Chemistry, Food Biosciences and Pharmacy, University of Reading,

Whiteknights, Reading RG6 6AD, U.K.

${ }^{\ddagger}$ Department of Applied Physics, Aalto School of Science, P.O. Box 15100, FI-00076 Aalto, Finland.

*Author for correspondence. E-mail: V.Castelletto@reading.ac.uk 


\section{Abstract}

Here we study the self-assembly of arginine capped bolaamphiphile peptide $R_{3} R$ (A: alanine, $\mathrm{R}$ : arginine) together with its binding to model membranes and $\mathrm{RA}_{3} \mathrm{R}$ cytotoxic and antimicrobial activities. Anionic 2-oleoyl-1-palmitoyl-sn-glycero-3-phospho-rac-(1glycerol) sodium salt/ 2-oleoyl-1-palmitoyl-sn-glycero-3-phosphoethanolamine (POPG/POPE) vesicles and zwitterionic 1,2-dioleoyl-sn-glycero-3-phosphocholine/ 2-oleoyl1-palmitoyl-sn-glycero-3-phosphocholine (POPC/DOPC) vesicles are used as model membranes to mimic bacterial and mammalian cell membranes respectively. We show that $R A_{3} R$ adopts a polyproline II collagen-like conformation in water. Binding of $R A_{3} R$ to POPG/POPE vesicles induces a strong correlation between the lipid bilayers, driven by $\mathrm{RA}_{3} \mathrm{R} / \mathrm{POPG}$ attractive electrostatic interaction together with a shift of the intramolecular POPE zwitterionic interaction towards an attractive electrostatic interaction with the $R A_{3} R$. Populations of $R A_{3} R / P O P G / P O P E$ vesicles comprise different bilayer spacings $d_{A}$ and $d_{B}$, controlled by the conformation of the lipid chains corresponding to the $L_{\beta}$ (gel-like) and $L_{\alpha}$ (liquid-crystal) phases respectively. Cryo-TEM images reveal the presence of vesicles with no internal structure, compartmentalized thin wall vesicles or multilayer vesicles with uncorrelated layers and compartmentalization, depending on the $\mathrm{RA}_{3} \mathrm{R} / \mathrm{POPG} / \mathrm{POPE}$ composition. In contrast, the interaction of $\mathrm{RA}_{3} \mathrm{R}$ with multilamellar POPC/DOPC vesicles leads to the de-correlation of the lipid bilayers. $R A_{3} R$ was tolerated by skin fibroblast cells for a concentration up to $0.01 \mathrm{wt} \%$, while $0.25 \mathrm{wt} \% \mathrm{RA}_{3} \mathrm{R}$ probed to be an efficient antibacterial agent against Gram-positive bacteria L. monocytogenes. Our results highlight the ability of $\mathrm{RA}_{3} \mathrm{R}$ to distinguish between bacterial and mammalian cells and set this peptide as a candidate to reduce proliferation of $L$. monocytogenes bacteria. 


\section{Introduction}

The development of innovative antimicrobial agents is attracting great interest because of the major global healthcare challenge of emerging antimicrobial resistance (AMR) to currently available drugs. Antimicrobial peptides are an important class of antimicrobials since they have evolved naturally in many plants and organisms and these can be exploited directly, or used as a basis for biomimetic antimicrobial peptide development.

A surfactant-like peptide (SLP) is conventionally considered to be a peptide comprising a short hydrophobic peptide sequence attached to a sequence of charged residues. This class of peptide was originally developed by S. Zhang et al. ${ }^{1-4}$ Examples include peptides with hydrophobic glycine, valine or alanine repeats and charged headgroups (either cationic or anionic), for instance $G_{8} D_{2}, H_{2} V_{6}, V_{6} D_{2}, A_{6} K, A_{6} D$, etc. Our group has previously studied the self-assembly of $A_{6} K,{ }^{5-6} A_{6} H,{ }^{7} A_{6} R,{ }^{8} A_{6} R G D^{9}$ and $A_{6} D^{10}$ among others. All these SLPs aggregate above defined critical aggregation concentrations (CACs). $A_{6} K$ forms nanotubes in concentrated aqueous solution. ${ }^{5-6,11} A_{6} H$ forms nanotapes, the morphology of which can be tuned using $\mathrm{pH}$ and $\mathrm{ZnCl}_{2}$ (which coordinates with the histidine residue). ${ }^{7} A_{6} R$ self-assembly motif in aqueous solutions can be changed from nanosheets into helical ribbons and nanotubes upon increasing the concentration of the sample. ${ }^{8} A_{6} R G D$ incorporates the RGD cell adhesion motif, and forms fibrils or vesicles in water as a function of the concentration. ${ }^{9} \mathrm{~A}_{6} \mathrm{D}$ self-assembles into nanosheets. ${ }^{10}$

SLPs have remarkable self-assembly properties and a diversity of applications. For example, $A_{6} D$ can replace surfactants in the production of soluble G-protein coupled receptors using $E$. coli cell-free systems. ${ }^{12} \mathrm{~A}_{6} \mathrm{D}$ can potentially be used in drug delivery formulations, since the SLP forms nanovesicles at physiological conditions. ${ }^{13}$ However in another paper from the same group, nanotubes, or nanotubes with bulges (which also appear to be like bead aggregate structures) were reported under the same conditions. ${ }^{14}$ Most relevant to the present paper, SLPs incorporating cationic head groups have been 
shown to have antimicrobial activity. Recent work ${ }^{15}$ shows that although addition of $A_{3} K$ did not reduce the number of bacteria, $\mathrm{A}_{6} \mathrm{~K}$ and $\mathrm{A}_{9} \mathrm{~K}$ show antimicrobial activity against Gramnegative E.coli and Gram-positive S. aureus. ${ }^{15}$ The antibacterial activity increases with increasing hydrophobicity, which also influences self-assembly since $A_{3} K$ forms ill-defined aggregates, whereas it was reported that $A_{6} K$ and $A_{9} K$ form elongated nanostructures. ${ }^{15}$ The peptide $A_{6} R$ shows antimicrobial activity against the same bacteria, however with greater activity against $S$. aureus. ${ }^{16}$ The interaction of this peptide with zwitterionic DPPC [1,2dipalmitoyl-sn-glycero-3-phosphocholine] lipid membranes was also investigated, and a lack of lysis with this type of membrane (of the same class as the membranes of eukaryotes) was noted. ${ }^{16}$ Peptide bolaamphiphiles (with charged residues at both ends) are another class of surfactant-like peptide. In particular, the self-assembly of SLPs including $\mathrm{I}_{2} \mathrm{~K}_{2} \mathrm{I}_{2}$ and $\mathrm{KI}_{4} \mathrm{~K}$ were investigated and the sequence change was found to profoundly influence aggregation since the former shows no defined nanostructure (and there is no evidence for $\beta$-sheet formation) whereas the latter forms nanotubes based on $\beta$-sheet hydrogen bonding. ${ }^{17-18}$ The self-assembly of arginine peptide bolaambolaamphiphile $\mathrm{RFL}_{4} \mathrm{FR}$ has been investigated and its compatibility with cells (fibroblasts) was demonstrated. ${ }^{19}$

Here, we report on the self-assembly and antimicrobial activity of the novel SLP $\mathrm{RA}_{3} \mathrm{R}$ incorporating arginine residues at both termini. In this process, we also report the interaction of $R A_{3} R$ with lipid membranes representing the cell wall of bacteria (vesicles containing mixtures of POPG/POPE lipids) or animals (vesicles containing mixtures of DOPC/POPC lipids). POPG indicates 2-oleoyl-1-palmitoyl-sn-glycero-3-phospho-rac-(1glycerol) sodium salt, POPE denotes 2-oleoyl-1-palmitoyl-sn-glycero-3phosphoethanolamine, DOPC denotes 1,2-dioleoyl-sn-glycero-3-phosphocholine and POPC denotes 2-oleoyl-1-palmitoyl-sn-glycero-3-phosphocholine. Vesicle compositions are based on the knowledge that lipids from the phosphatidylethanolamine (PE) and phosphatidylglycerol (PG) classes are the most abundant lipids in the composition of 
bacterial membranes ${ }^{20}$ while POPC is the major lipid component of mammalian membranes. ${ }^{21}$

Here we use a range of microscopy and spectroscopy techniques and small-angle Xray scattering (SAXS) to probe the assembly and conformation of $R A_{3} R$ in water and its interaction with model lipid membranes. Finally, we evaluate the cytotoxicity and antimicrobial activity of $\mathrm{RA}_{3} \mathrm{R}$.

\section{Experimental}

Samples. Peptide $R A_{3} R$ was custom synthesized by Biomatik (UK). The peptide was received as a TFA salt, the purity was determined by the supplier to be $96.86 \%$ as determined from HPLC (0.1 \% TFA in water/ acetonitrile gradient). Mw= $543.63 \mathrm{Da}$ was measured by electro-spray ionization mass spectroscopy (ESI-MS) analysis. Lipids POPG $(\mathrm{Mw}=770.99 \mathrm{Da})$, POPE $(\mathrm{Mw}=718 \mathrm{Da})$, DOPC $(\mathrm{Mw}=786.11 \mathrm{Da})$ and POPC $(\mathrm{Mw}=760.08$ Da) were purchased from Sigma Aldrich (UK) and used as received. $R A_{3} R$ is positively charged in water $(+2)$. POPE, POPC and DOPC are zwitterionic in water. POPG is negatively charged in water $(-1)$. Scheme 1 displays the chemical structures for $R A_{3} R$, POPE, POPC, DOPC and POPG.

Vesicle preparation. Vesicles were prepared by the thin layer hydration method, used in previous studies on binary POPE/POPG vesicles. ${ }^{22}$ Weighted quantities of lipids were dissolved in chloroform. Thin films of lipids were obtained by drying the chloroform under a stream of nitrogen. Traces of the organic solvent were removed by placing the lipid films in a vacuum chamber for 2 hrs. Lipid films were then re-suspended in a weighted quantity of water corresponding to $0.5 \mathrm{wt} \%$ lipid. Lipid solutions were vortexed for 5 minutes (1800 rpm; $55^{\circ} \mathrm{C}$ ) and left to equilibrate before experiments. POPG/POPE anionic vesicles were made using mixtures of lipids at different molar ratios to provide POPG molar fractions $\phi_{\mathrm{POPG}}=$ $[P O P G] /([P O P G]+[P O P E])=1,0.6,0.5,0.4,0.2$ and 0 ([ ]: molar concentration) which corresponds to a POPG/POPE \% content (e.g, \% POPE $=100 \times$ weight 
POPE/weight(POPE+POPG)) of 100, 65/35, 50/50, 44/56, 27/73 and 0. Zwitterionic vesicles were made by mixing POPC and DOPC lipids at a molar ratio to provide a DOPC molar fraction $\phi_{\mathrm{DOPC}}=[\mathrm{DOPC}] /([\mathrm{POPC}]+[\mathrm{DOPC}])=0.2$ which corresponds to a POPC/DOPC \% content of $80 / 20$. Samples containing $R A_{3} R$ and lipids were made by adding a weighed quantity of $R A_{3} R$ powder to solutions of 0.5 wt\% lipid vesicles, in order to obtain $0.08,0.25$ or 0.5 wt $\% R^{2} A_{3} R$. The mixtures were then vortexed for 5 minutes $\left(1800 \mathrm{rpm}, 55^{\circ} \mathrm{C}\right)$ and left to equilibrate before experiments.

In the following we will omit the concentration of POPG/POPE and POPC/DOPC mixtures because it was kept at $0.5 \mathrm{wt} \%$ for all the samples. The composition of each sample will be indicated only by the relevant mole fraction of lipid ( $\phi_{\mathrm{POPG}}$ or $\phi_{\mathrm{DOPC}}$ ) and the concentration of $R A_{3} R$ in wt\%.

Circular Dichroism (CD) Spectroscopy. CD spectra were recorded using a Chirascan spectropolarimeter (Applied Photophysics, UK). Solutions were placed in a quartz cover slip cuvette $(0.01 \mathrm{~mm}$ thick). Spectra were measured using a $0.5 \mathrm{~nm}$ step, $1 \mathrm{~nm}$ bandwidth, and 1 s collection time per step. Only data with absorbance $A<2$ was recorded during the experiments. The CD data is corrected by the CD signal from the water background. Where data has been smoothed, the smoothed spectra present no distortions in the residual trace.

Fourier Transform Infra-Red (FTIR) Spectroscopy. FTIR data were recorded using a Nexus-FTIR spectrometer equipped with a DTGS detector. Solutions were measured using the PEARL liquid transmission accessory. Spectra were measured for wavenumbers in the range $900-4000 \mathrm{~cm}^{-1}$. Each spectrum was scanned 128 times.

Small-Angle and X-Ray Scattering (SAXS). Synchrotron SAXS experiments were performed using BioSAXS robots on beamline BM29 (ESRF, France) and on beamline B21 (Diamond Light Source Ltd., ESRF). On BM29 and B21, the solutions were manually loaded into the 96 well plate of an EMBL BioSAXS robot. The robot injected the solutions into a quartz capillary (1.8 $\mathrm{mm}$ internal diameter) placed in front of the X-ray beam. After the 
sample was injected in the capillary and reached the X-ray beam, the flow was stopped for the acquisition of the SAXS data. The quartz capillary was enclosed in a vacuum chamber to avoid parasitic scattering. B21 operated with a $3.9 \mathrm{~m}$ camera length and $12.4 \mathrm{keV}$ energy. The images were captured using a Pilatus $2 \mathrm{M}$ detector. Data was corrected by background subtraction and then radially averaged, using the dedicated beamline software ScÅtter. BM29 operated with an X-ray wavelength $\lambda=1.03 \AA(12 \mathrm{keV})$. The images were captured using a PILATUS $1 \mathrm{M}$ detector, while data processing was performed using dedicated beamline software ISPYB (BM29).

Cryogenic Transmission Electron Microscopy (Cryo-TEM). Experiments were carried out using a field emission cryo-electron microscope (JEOL JEM-3200FSC) operating at $300 \mathrm{kV}$. Images were taken using bright-field mode and zero loss energy filtering (omega type) with a slit with $20 \mathrm{eV}$. Micrographs were recorded using a Gatan Ultrascan 4000 CCD camera. The specimen temperature was maintained at $-187^{\circ} \mathrm{C}$ during the imaging. Vitrified specimens were prepared using an automated FEI Vitrobot device using Quantifoil 3.5/1 holey carbon copper grids with $3.5 \mu \mathrm{m}$ hole sizes. Grids were cleaned using a Gatan Solarus 9500 plasma cleaner just prior to use and then transferred into an environmental chamber of FEI Vitrobot at room temperature and $100 \%$ humidity. Thereafter, $3 \mu \mathrm{l}$ of sample solution with $0.5 \mathrm{wt} \%$ concentration was applied on the grid, blotted once for 1 second and then vitrified in a 1/1 mixture of liquid ethane and propane at $-180^{\circ} \mathrm{C}$. Grids with vitrified sample solutions were maintained in a liquid nitrogen atmosphere and then cryo-transferred into the microscope.

Cell Viability assays. The cytotoxicity of $\mathrm{RA}_{3} \mathrm{R}$ was examined. In vitro cell culture was conducted using the $161 \mathrm{br}$ (ECACC) human skin fibroblast cell line. Cells were cultured in EMEM, with 2 mM glutamine, enriched with 15\% fetal bovine serum (FBS), 1\% non-essential amino acids (NEAA) and 1\% antibiotic-antimycotic (100x). Cells were maintained in a humidified atmosphere of $5 \% \mathrm{CO}_{2}$ at $37^{\circ} \mathrm{C}$. Cytotoxicity was examined using the MTT (3(4,5-dimethylthiazol-2-yl)-2,5-diphenyltetrazolium bromide) assay. $\mathrm{RA}_{3} \mathrm{R}$ was dissolved in complete medium. Cells were seeded into a 96-well plate at a seeding density of $4 \times 10^{4}$ 
cells $/ \mathrm{mL}$, and allowed to adhere for 24 hours in $100 \mu \mathrm{L}$ complete medium. After 24 hours, a total volume of $100 \mu \mathrm{L}$ of either complete medium and/or peptide solution was added, to give final peptide concentrations of $0.5,0.25,0.1,0.05,0.01$ or $0.005 w t \% R A_{3} R$. After 67 hours of incubation, $20 \mu \mathrm{L}$ of MTT ( $5 \mathrm{mg} / \mathrm{mL}$ in PBS) was added to each well plate and allowed to incubate for 5 hours (total of 72 hours incubation). After this, the solution was removed from each well and replaced with $100 \mu \mathrm{L}$ DMSO per well in order to dissolve the formazan crystals. Plates were incubated for 30 minutes, and then analysed using a UV microplate reader $(\lambda=570 \mathrm{~nm})$. Results are reported as a percentage cell viability compared to control (untreated values). The ANOVA and Bonferoni post hoc tests were used to check statistical significance.

Bacterial strains and growth conditions. Experiments were performed with three different microorganisms namely, Staphylococcus aureus, Listeria monocytogenes and Escherichia coli. The strains used were a wild type strain of Staphylococcus aureus previously isolated from ham $^{23}$ a widely-used wild type strain of $L$. monocytogenes (LO28;24-25) and one of the most widely-used E. coli strains (K-12). Stock cultures were stored at $-80^{\circ} \mathrm{C}$ in $7 \%(\mathrm{vol} / \mathrm{vol})$ DMSO (Sigma-Aldrich, Dorset, UK). Prior to experiments, stock cultures of $S$. aureus and $L$. monocytogenes were streaked onto brain heart infusion (BHI) agar (LAB M, Lancashire, UK) while those of E. coli were streaked onto Lysogeny Broth (LB) agar (Oxoid, UK) and incubated overnight at $37^{\circ} \mathrm{C}$.

Preparation of cell suspension. Three colonies from these cultures were then transferred to $3 \mathrm{ml}$ sterile Tryptone soy broth (TSB) supplemented with $0.3 \%(\mathrm{w} / \mathrm{v})$ yeast extract (TSBY) (Oxoid, UK) and grown at $37^{\circ} \mathrm{C}$ under agitation at 150 rev $\min ^{-1}$ on a Gallenkamp orbital shaker for $24 \mathrm{~h}$. Subsequently, $20 \mathrm{ml}$ of TSB broth was inoculated with the previously prepared overnight cultures up to $1 \%$ and grown at $37^{\circ} \mathrm{C}$ under agitation at 150 rev min $^{-1}$ for a further 24 hours. These cultures were used for the subsequent experiments. 
The viability of the cultures was assessed before use by serially diluting in Maximum Recovery Diluent (MRD, Oxoid) and plating onto nutrient agar. Cultures were transferred into $50 \mathrm{ml}$ falcon tubes (VWR UK) and cells were harvested by centrifugation at $9000 \mathrm{rpm}$ and 4 ${ }^{\circ} \mathrm{C}$, for $10 \mathrm{~min}$ in an Eppendorf 5804 centrifuge. The supernatant was then discarded and the pellet was re-suspended in $1.5 \mathrm{~mL}$ ice chilled PBS. Twenty $\mu$ l of this solution was then transferred into $200 \mu \mathrm{l}$ of $\mathrm{RA}_{3} \mathrm{~A}$ peptide solution (0.25 wt\%) which had been prepared in sterile water. Control solutions were made by inoculating $200 \mu \mathrm{l}$ of sterile water with $20 \mu \mathrm{l}$ of the PBS suspended culture. Solutions were then vortexed for 3 seconds and samples taken at $0,30,60,120$ and $1440 \mathrm{~min} .100 \mu \mathrm{l}$ of the peptide culture solution was then serially diluted in MRD and subsequently $10 \mu \mathrm{l}$ of each dilution was plated onto plate count agar (PCA) and incubated at $37^{\circ} \mathrm{C}$ for 24 hours before the enumeration of colonies.

\section{Results and Discussion}

We first examined the self-assembly of $R A_{3} R$ in water. CD, FTIR and SAXS data are shown in Figure 1.

The CD spectra for $0.08-0.5 \mathrm{wt} \% \mathrm{RA}_{3} \mathrm{R}$ show a deep minimum at $190 \mathrm{~nm}$ along with a broad positive maximum at around $220 \mathrm{~nm}$ (Figure 1a); a signature of polyproline II (collagen-like) secondary structure. ${ }^{26-34}$ This structure has been observed for other short polyalanine peptides. ${ }^{32}$

FTIR spectra for 2, 0.5, 0.25 and 0.08 wt $\% \mathrm{RA}_{3} \mathrm{R}$ show bands at 1672,1587 and $1608 \mathrm{~cm}^{-1}$ (Figure 1b). The peak at $1672 \mathrm{~cm}^{-1}$ is due to bound TFA counterions. ${ }^{35-37}$ FTIR bands at 1587 and $1608 \mathrm{~cm}^{-1}$ are related to vibrational bands associated with the side chains of the R-residues. ${ }^{38-39}$ In addition, the 2 wt $\% \mathrm{RA}_{3} \mathrm{R}$ sample shows a FTIR band at $1675 \mathrm{~cm}^{-1}$, which consistent with the CD spectra, is characteristic of short polyalanine peptides with a PPII structure..$^{40-41}$ 
Figure 1c shows the SAXS data for 0.5 and $10 \mathrm{wt} \% \mathrm{RA}_{3} \mathrm{R}$. The SAXS data for 0.08 and 0.25 wt\% $\mathrm{RA}_{3} \mathrm{R}$ had very poor statistics and therefore has not been included in the manuscript. Since the SAXS data for $0.5 \mathrm{wt} \% \mathrm{RA}_{3} \mathrm{R}$ is relatively weak, the SAXS data for 10 $w t \% \mathrm{RA}_{3} \mathrm{R}$ has been included in Figure $1 \mathrm{c}$ as a reference. SAXS data for 0.5 and $10 \mathrm{wt} \%$ $\mathrm{RA}_{3} \mathrm{R}$ (Figure 1c) was modelled according to a Gaussian coil model using the SASfit program. ${ }^{42-43}$ The parameters of this model are the radius of gyration of the Gaussian chain $R_{g}$ and the excluded volume parameter $v$. The fitted models provided $R_{g}=4.8,8.9 \AA$ and $v=$ $0.43,0.6$ for 10 and $0.5 w t \% \mathrm{RA}_{3} \mathrm{R}$ respectively. The excluded volume parameter $v$ indicates a swollen conformation of the peptide chain at 0.5 wt $\% \mathrm{RA}_{3} \mathrm{R}$, and a relatively folded conformation of the peptide chain at $10 w t \% R A_{3} R$. Cryo-TEM on $1 w t \% R A_{3} R$ did not show the formation of any nanostructure (results not shown).

These results indicate that $R A_{3} R$ does not self-assemble in water, probably due to the high solubility due to the two terminal $\mathrm{R}$ residues and the flexibility of PPII structure. Therefore, in the following we will focus on the interaction of $R A_{3} R$ with model anionic and zwitterionic membranes.

Table S1 lists the POPG/POPE $+\mathrm{RA}_{3} \mathrm{R}$ mixtures studied in this work along with the appearance of the solutions. POPG/POPE vesicles with $\phi_{\mathrm{POPG}}=1,0.6,0.5,0.4,0.2$ or 0 were mixed with $0,0.08,0.25$ or 0.5 wt $\% \mathrm{RA}_{3} \mathrm{R}$. In this way, the influence of the lipid composition in mixtures at a given peptide concentration was examined while additionally the influence of peptide concentration was probed. Table S1 shows that homogeneous cloudy samples were obtained for $\phi_{\mathrm{POPG}}=1,0.6,0.5,0.4,0.2$ or $0+0 \mathrm{wt} \% \mathrm{RA}_{3} \mathrm{R}$, for $\phi_{\mathrm{POPG}}=1,0.6,0.5,0.4$ or 0.2 $+0.08 w t \% R A_{3} R$ and for $\phi_{P O P G}=0.6,0.5,0.4$ or $0.2+0.25 w t \% R A_{3} R$. But phase separation (sample precipitation) was observed for other samples.

Figure 2 shows the SAXS data measured for samples in Table S1. Spacings $d$, measured from the position of the peaks in the SAXS data $\left(d=2 \pi / q_{0} ; q_{0}=\right.$ position of the peak maximum), are displayed in Figure 2. Table 1 shows representative examples, as a 
function of $\phi_{\mathrm{POPG}}$, for the indexation of the spacings $d$ displayed in Figure 2. SAXS data in Figure 2 for samples with $\phi_{P O P G}=1,0.6$ or $0.4+0.5 w t \% R A_{3} R$ is dominated by the scattering from the precipitate, as cryo-TEM results later in the text show that there are no vesicles in the supernatant.

We first consider the SAXS profiles of the lipid mixtures without added peptide. The SAXS data in Figure 2 was measured at $20^{\circ} \mathrm{C}$. A previous SAXS study of POPG/POPE vesicles shows that at $20^{\circ} \mathrm{C}$, samples with $\phi_{\mathrm{POPG}}=0$ are in the $\mathrm{L}_{\beta}$ (gel-solid ordered phase) phase, samples with $\phi_{\mathrm{POPG}}=0.2$ are at the $L_{\beta} / L_{\alpha}$ (fluid disordered liquid crystal phase) phase co-existence point, and samples with $0.4 \leq \phi_{\mathrm{POPG}} \leq 1$ are in the $L_{\alpha}$ phase. ${ }^{22}$ Here, we measured a lamellar spacing of $61.6 \AA$ for $\phi_{\mathrm{POPG}}=0$ in the $\mathrm{L}_{\beta}$ (gel) phase (Table 1), in good agreement with data in the literature..$^{22}$ SAXS for $0.2 \leq \phi_{\mathrm{POPG}} \leq 1$ shows a broad peak centred at $q \sim 0.1 \AA^{-1}$, which was previously ascribed to MLVs (with walls consisting of freely fluctuating and uncorrelated bilayers) for $0.4 \leq \phi_{P O P G}<1$, but to unilamellar vesicles for ${ }_{P O P G}=1$ (the negative charge of the lipids leads to a net electrostatic repulsion of the bilayers)..$^{22}$

Figures $2 a-e$ shows that addition of $R A_{3} R$ to samples with $\phi_{P O P G}=1,0.6,0.5,0.4$ and 0.2 induces a strong correlation between bilayers, corresponding to a lamellar order denoted by the presence of scattering peaks in the SAXS curves. Noticeably, increasing the peptide concentration does not alter the position of the scattering peaks for a fixed $\phi_{\mathrm{POPG}}$, but it can increase the order of the reflexions in the SAXS pattern (e.g. Figure 2a-c). The $\mathrm{RA}_{3} \mathrm{R}$ induced bilayer order is divided in two populations with lamellar cell parameter $d_{A}$ or $d_{B}$, which increases from 70.9 to $72.9 \AA$ and from 59.3 to $63.7 \AA$ respectively, for POPG fractions decreasing from 1 to 0.2 (Figure 2, Table 1 ). In contrast, the addition of $\mathrm{RA}_{3} \mathrm{R}$ to samples containing $\phi_{\mathrm{POPG}}=0(100 \% \mathrm{POPE})$ does not induce any order different from the lamellar spacing at $61.6 \AA$ measured at $0 \mathrm{wt} \% \mathrm{RA}_{3} \mathrm{R}$ (Figure $2 \mathrm{f}$, Table 1). 
The SAXS data in Figure 2 was fitted using models for the form factor and structure factor of lamellar structures, in an attempt to get a closer insight into the nanostructure of the solutions. Details of the model ${ }^{44}$ are provided in the Supplementary Information. We only fitted the data for the samples in Figure $2 \mathrm{c}$, containing $\phi_{\mathrm{POPG}}=0.5$ and $0-0.5 \mathrm{wt} \% \mathrm{RA}_{3} \mathrm{R}$, as a representative result for the data plotted in Figure 2 with $1 \leq \phi_{\mathrm{POPG}}<0$. Fits to the SAXS data in Figure 2c data are displayed in Figure S1. Fitting parameters, listed in Table S2, were used to calculate the electron density distribution across the bilayers (Figure S2).

Results obtained from the fitting of the SAXS data describe the formation of two co-existing bilayers upon addition of $R A_{3} R$ to the sample (bilayers $A$ and $B$, Table S2). SAXS fittings provide the distance between the lipid headgroups, $I_{H}$ (Table S2). The water layer thickness between bilayers, $l w$, can be estimated from the bilayer repeat distance $\left(d_{A}=71.7 \AA\right.$ or $d_{B}=$ $61.2 \AA$, Table 1) minus $l_{H}$, according to $l w, i=d_{\Gamma} l_{H}(i=\mathrm{A}, \mathrm{B})$.

Our results provide $l_{w, A}=13.5$ or $13.6 \AA$ for 0.25 or 0.5 wt $\% \mathrm{RA}_{3} \mathrm{R}$ respectively and $l_{w, B}=$ $13.1,13.2$ or $13.1 \AA$ for $0.08,0.25$ or 0.5 wt $\% \mathrm{RA}_{3} \mathrm{R}$ respectively. Parameters $l_{w, A}$ and $l_{w, B}$ are similar for all samples in Table S2. This is in contrast with $l_{\mathrm{H}} \sim 58 \AA$ for bilayers $A$ against $l_{H} \sim 48 \AA$ for bilayers B (Table S2). As a whole, results in Figure S1 and Table S2 confirm that $d_{\mathrm{A}}$ and $d_{\mathrm{B}}$ in Table 1 originate from two populations of lipid bilayers with different $l_{\mathrm{H}}$ but similar $l_{w}$.

The nanostructure of the samples containing peptides, studied in Figure 2 and Table S1, was also investigated by cryo-TEM. Cryo-TEM images correspond to the supernatant or to the bulk sample, for samples presenting precipitation or for homogeneous samples respectively (Table S1). Following the inspection of all cryo-TEM images, it is possible to classify vesicles according to the three types displayed in Figure 3. The first are simple thin wall vesicles, which may be unilamellar vesicles (confirmed by SAXS), the second are thin wall vesicles with internal structure, i.e. internal compartmentalization and the third are multilamellar vesicles with uncorrelated layers and typically (but not necessarily) internal 
compartmentalization. The classification of vesicles according to Figure 3 is modified from that introduced in ref. ${ }^{22}$ for POPG/POPE vesicles in the absence of peptide. Table 2 summarizes vesicle morphologies identified by cryo-TEM. Figures S3 to Figure S8 show cryo-TEM images from all samples.

A repeat distance between bilayers $d_{\text {cryo }}$ could be measured in some cryo-TEM images (e.g. inset in Figures S4b, S5a and S6b). However, $d_{\text {cryo, }}$ listed in Table 2, cannot be solely assigned to $d_{A}$ or $d_{B}$ measured by SAXS because the error in cryo-TEM measurements $(\sim 10 \AA)$ falls within the difference between $d_{\mathrm{A}}$ and $d_{\mathrm{B}}$.

In an attempt to understand the role of electrostatic effects on the interaction of $\mathrm{RA}_{3} \mathrm{R}$ with POPG/POPE vesicles, we studied the interaction of this peptide with zwitterionic DOPC/POPC MLVs by SAXS.

Figure 4 shows the SAXS measured for a sample containing $\phi_{\mathrm{DOPC}}=0.2$ with $0,0.8$, 0.25 and $0.5 \mathrm{wt} \% \mathrm{RA}_{3} \mathrm{R}$. The SAXS for samples with only $\phi_{\mathrm{DOPC}}=0.2$ displays two peaks in a positional ratio $1: 2$ corresponding to a lamellar spacing of $64.4 \AA$ (Figure 4). To our knowledge there are no previous records in the literature for the lamellar spacing of POPC/DOPC MLVS. However, a lamellar repeat distance of $\sim 63 \AA$ has been reported for POPC MLVs at room temperature ${ }^{45}$ while lamellar spacings of $62.5 \AA$ and $63.1 \AA$ have been reported for DOPC MLVs at room temperature ${ }^{46}$ and $30{ }^{\circ} \mathrm{C}^{47}$ respectively. Figure 4 shows that gradual addition of $\mathrm{RA}_{3} \mathrm{R}$ induces the de-correlation of the lipid bilayers.

The different effects produced in the SAXS curves by adding $\mathrm{RA}_{3} \mathrm{R}$ to POPG/POPE vesicles (Figure 2) or POPC/DOPC vesicles (Figure 4) can be attributed to the electrostatic interaction between $R A_{3} R$ and the lipids.

SAXS data in Figure 4 was fitted using the same method described before to fit the SAXS data in Figure 2c. The fitted SAXS data is shown in Figure S9 while the parameters extracted from the fitting are listed in Table S3. The electron density profile of the bilayers, 
calculated with parameters listed in Table S3 is displayed in Figure S10. The extracted parameters describe the de-correlation of bilayers induced upon addition of $R_{3} R$ to $\phi_{\mathrm{DOPC}}=0.2$ vesicles. This is denoted by the decrease in the length of correlation of the bilayers from $N=8$ to $N=2$ by adding 0.5 wt $\% R A_{3} R$ to the zwitterionic bilayers.

Figure 5a shows a representative cryo-TEM image for a sample only with $\phi_{\mathrm{DOPC}}=0.2$. There is co-existence of vesicles type (i), (ii) and (iii) described in Figure 3. Some of the vesicles show a spacing $(6.2 \pm 1.3) \mathrm{nm}$ at the walls, similar to the lamellar spacing $64.4 \AA$ measured by SAXS for $0.5 w t \% \phi_{\mathrm{DOPC}}=0.2$ (Figure 4). Figure $5 \mathrm{~b}$ shows that for $\phi_{\mathrm{DOPC}}=0.2+$ $0.5 w t \% R A_{3} R$, the destabilization of lipid bilayers suggested by the SAXS data in Figure 4, corresponds to decreased correlation of lipid bilayers in type (iii) vesicles. The is confirmed by SAXS which shows a broad peak in the intensity profile, instead of Bragg reflections (Figure 4).

It is likely that $R A_{3} R$ is adsorbed at either side of POPC/DOPC bilayers. Consequently, a net positive charge is added to the bilayer surface, increasing the repulsion between bilayers and therefore reducing their correlation length. A similar effect was reported to us for the interaction of the peptide $A_{6} R$ with zwitterionic MLVs of DPPC. ${ }^{16}$ On the other hand, electrostatic interactions between $R A_{3} R$ and POPG/POPE vesicles increase the correlation between lipid bilayers. In contrast to POPC and DOPC, the positively charged $\mathrm{NH}_{3}{ }^{+}$group in POPE is exposed to water. In contrast to POPC and DOPC, the positively charged $\mathrm{NH}_{3}{ }^{+}$group in POPE is exposed to water. In the presence of $\mathrm{RA}$ R, the balance of the zwitterionic interaction between the phosphate group and the $\mathrm{NH}_{3}{ }^{+}$group in the POPE may be driven towards favouring the interaction between the positively charged $R A_{3} R$ and the phosphate group of the POPE. An attractive electrostatic interaction between the $R A_{3} R$ and POPG is expected due to their opposite charges.

The interaction between alanine-based short peptides and anionic or zwitterionic small unilamellar vesicles (SUVs) has been reported in a previous study. ${ }^{15}$ Similarly to results presented here, it was found that $A_{9} K$ strongly interacts with the membrane at the 
wall of phosphatidylglycerol SUVs, causing a strong disruption of its structure, but barely affects the membrane of phosphatidylcholine SUVs.

The thermal stability of lamellar phase spacings was tested through temperature ramp-SAXS experiments on the sample with $\phi_{P O P G}=0.4+0.08$ wt $\% R A_{3} R$. Figure 6 displays the SAXS results where the temperature was increased from 10 to $60^{\circ} \mathrm{C}$ and subsequently decreased to $20{ }^{\circ} \mathrm{C}$. The spacing $d_{A}$ is $70.9 \AA$ at $10{ }^{\circ} \mathrm{C}$ and $73 \AA$ at $20{ }^{\circ} \mathrm{C}$, disappears between 30 and $60{ }^{\circ} \mathrm{C}$, but it appears again as $d_{A}=72.3 \AA$ when the temperature is decreased from 60 to $20^{\circ} \mathrm{C}$. Spacing $d_{B}$ gradually changes from 61.9 into $58.3 \AA$ when the temperature increases from 10 to $60^{\circ} \mathrm{C}$, but it returns to $d_{B}=63.7 \AA$ when the temperature is decreased from 60 to $20{ }^{\circ} \mathrm{C}$. Lipid bilayers with lamellar spacing $d_{B}$ resist temperature changes, while lipid bilayers with lamellar spacing $d_{A}$ are stable only up to $20^{\circ} \mathrm{C}$. It is likely that $d_{A}$ corresponds to lipid chains in the $\mathrm{L}_{\beta}$ (gel-solid ordered phase) conformation, which changes into the $L_{\alpha}$ (fluid disordered liquid crystal phase) conformation with spacing $d_{B}$, upon raising the temperature. Extrapolating these results, $d_{A}$ and $d_{B}$ listed in Table 1 for samples containing $R A_{3} R$, originate from two populations of lipid chains in the $L_{\beta}\left(d_{A}\right)$ or in the $L_{\alpha}\left(d_{B}\right)$ phase. This hypothesis points to a phase co-existence of both phases for mixed peptide/lipid samples in Figure 2, with $\phi_{\mathrm{POPG}}>0$.

MTT assays, using $161 \mathrm{Br}$ skin fibroblast cells, were performed to evaluate the cytocompatibility of $\mathrm{RA}_{3} \mathrm{R}$. Viability results (Figure 7 ) show that the peptide was tolerated by the cells up to a concentration of $0.01 \mathrm{wt} \%$. But above this concentration there is a steady decrease in cell proliferation, such that cell viability is reduced from $78 \%$ to $34 \%$ when the peptide concentration is increased from 0.05 to $0.5 \mathrm{wt} \%$. Since $R A_{3} R$ does not self-assemble in solution, the reduction in cell viability might be triggered by the intrinsic effect of the cationic residues interacting with the PC lipids (cf. Figure 4).

To study the antimicrobial activity of the $\mathrm{RA}_{3} \mathrm{~A}$ peptide we selected both Gram negative and Gram positive microorganisms. The Gram negative bacteria was E. coli, which 
is one of the most studied microorganisms with a variety of pathogenic strains causing a range of negative health problems generally resulting from foodborne contamination. ${ }^{48}$ The two Gram positive bacteria were $S$. aureus, a highly key human nosocomial and foodborne pathogen and L. monocytogenes which currently is one of the deadliest foodborne pathogens with a mortality rate of $30 \% .^{23,49}$

Antimicrobial assays to assess the potential antimicrobial activity of $R_{3} A$, measured the survival of S. aureus, E. coli, and L. monocytogenes after exposure to the presence or absence of $0.25 w t \% R A_{3} R$ under aqueous conditions. The results are displayed in Figure 8.

An effect of the peptide treatment in the range of 3.5 orders of magnitude reduction of the CFU/ml was found against E. coli (Gram negative organism) which however, was not statistically significant. A major effect of $\mathrm{RA}_{3} \mathrm{~A}$ was found with $L$. monocytogenes, represented by a $5.6 \mathrm{log}$ reduction in CFU/ml (Figure 8). A less pronounced effect in the range of $2.6 \log$ reduction of the $\mathrm{CFU} / \mathrm{ml}$ was found for $\mathrm{RA}_{3} \mathrm{R}$ in contact with $S$. aureus. The $\mathrm{CFU} / \mathrm{ml}$ reduction effect was however statistically significant only for $L$. monocytogenes. This result is different from our previous experiments for closely related SLPs, which report the antimicrobial activity of $0.25 \mathrm{wt} \% \mathrm{~A}_{6} \mathrm{R}$ against $S$. aureus. ${ }^{16}$

Overall, a dramatic effect of this peptide on the numbers of $L$. monocytogenes was seen within the first hours of the challenge where approximately a 4 order of magnitude reduction occurred within the first 2 hours. In contrast, the effect on $E$. coli and $S$. aureus seemed to be steadier throughout time as the logarithmic reduction within the first $2 \mathrm{~h}$ was proportional to that which occurred within $24 \mathrm{~h}$. These results suggest a strong antibacterial effect on Gram positive bacteria and a possibly small but potentially significant impact on Gram negative organisms when exposed to high contractions of this type of peptide.

Here, antimicrobial assays are performed at $0.25 \mathrm{wt} \% \mathrm{RA}_{3} \mathrm{R}$ because we investigate bacteria survival within a few minutes. The concentration $0.25 w t \% R A_{3} R$ resulted in a reduction of fibroblast numbers by $\sim 40 \%$ (Figure 7) while it caused a reduction of about $4-5$ 
orders of magnitude in L. monocytogenes numbers (Figure 8c). Accordingly, if we started with 10,000 fibroblasts we would be left with 4,000 while with the same treatment we would be left with 1 out of 10,000 cells of L. monocytogenes. Furthermore, the effect on fibroblasts is after 67 hours incubation while that on Listeria is only after 1 hour. This demonstrates the compound is clearly highly antimicrobial.

L. monocytogenes contains $80-85 \%$ phospholipid of the PG type and $15-20 \%$ neutral lipid. ${ }^{50}$ This membrane composition is intermediate to $\phi_{\mathrm{POPG}}=1$ and $\phi \mathrm{POPG}=0.6$ in our work. We therefore argue that the antimicrobial activity of $0.25 w t \% R A_{3} R$ on $L$. monocytogenes (Figure 8) does not take place through membrane lysis, but through a re-organization of the membrane bilayers, similar to that shown in Figures 2a-b.

The antimicrobial activity of $\mathrm{RA}_{3} \mathrm{R}$ against $E$. coli (Gram negative) and $S$. aureus (Gram positive) can be compared to that reported in the literature for the closely related peptide $A_{3} K .{ }^{15}$ Similar to $R A_{3} R$, addition of 0 to 0.02 wt\% $A_{3} K$ to E. coli DH5a (Gram negative) or $S$. aureus (Gram positive) did not cause a great reduction in the number of bacteria. $^{15}$

\section{Conclusions}

Our results show that $R A_{3} R$ does not aggregate in water, but adopts a polyproline II collagen-like conformation for 0.08-0.5 wt\% peptide. Interaction of $\mathrm{RA}_{3} \mathrm{R}$ with model bacterial membranes (POPG/POPE vesicles) induces a strong correlation between the lipid bilayers. $\mathrm{RA}_{3} \mathrm{R}$ enhances the correlation POPG/POPE bilayers through the attractive electrostatic interaction with POPG together with the shift of the zwitterionic interaction in POPE towards an attractive electrostatic interaction with the peptide.

The walls of $R A_{3} R / P O P G / P O P E$ vesicles with $\phi P O P G ~>0$ present a co-existence of lamellar orders with cell parameters $d_{A}$ and $d_{B}$, which span a range $d_{A}=(70.9-72.9) \AA$ and 
$d_{B}=(59.3-63.7) \AA$ for $\phi_{\mathrm{POPG}}=0.2-1$. The cell parameters are controlled by the conformation of the lipid chain; $d_{A}$ and $d_{B}$ corresponding to the $L_{\beta}$ and $L_{\alpha}$ phases respectively. This hybrid lamellar order can build the walls of (i) thin wall vesicles with no internal structure, (ii) compartmentalized thin wall vesicles or (iii) multilayer vesicles with uncorrelated layers and compartmentalization. In contrast, the addition of $R A_{3} R$ to POPC/DOPC vesicles leads to the de-correlation of the lipid bilayers. In this case, the zwitterionic groups of the lipids are not exposed to water and therefore less likely to interact with $R A_{3} R$, preventing an increase in the bilayer correlation.

The affinity of $R A_{3} R$ for POPE/POPG membranes compared to the weak interaction with POPC/DOPC membranes shows the ability of $R A_{3} R$ to distinguish between bacterial and mammalian cells. In fact, $\mathrm{RA}_{3} \mathrm{R}$ was tolerated by skin fibroblast cells for a concentration of 0.01 wt $\%$, with cell viability highly reduced for $0.05-0.5$ wt $\% R A_{3} R$. However, 0.25 wt $\%$ $R A_{3} R$ probed to be an efficient antibacterial agent against $L$. monocytogenes, setting a precedent to develop new formulations containing $R A_{3} R$ as the active agent against $L$. monocytogenes bacteria.

Acknowledgements. This work was supported by EPSRC Platform Grant "Nanostructured Polymeric Materials for Healthcare" (EP/L020599/1). We are grateful to the ESRF for beamtime at BM29 (refs. MX1880 and MX1869) and Martha Brennich and Gabrielle Giachin for support during beamtimes at BM29. We thank Diamond Beamtime at B21 (refs. SM15778 and SM17118-1) and Katsuaki Inoue and Nathan Cowieson support during SAXS experiments at B21. 


\section{Supporting Information}

The Supporting Information is available free of charge on the ACS Publications


of parameters obtained from SAXS fittings, SAXS data and fittings and cryo-TEM images. 
Table 1. Representative examples, as a function of $\phi_{\mathrm{POPG}}$, for the indexation of the SAXS data in Figure 2: spacings $d$, measured from the position of the peaks in the SAXS data ( $d=$ $2 \pi / q_{0} ; q_{0}=$ position of the peak maximum), ratios between spacings showing a lamellar order and lamellar cell parameter $d_{i=A, B}$.

\begin{tabular}{|c|c|c|c|c|c|c|}
\hline & $\begin{array}{c}\phi P O P G=1+ \\
0.5 \text { wt } \% \mathrm{RA}_{3} \mathrm{R}\end{array}$ & $\begin{array}{c}\phi P O P G=0.6+ \\
0.25 w t \% R_{3} R\end{array}$ & $\begin{array}{c}\phi P O P G=0.5+ \\
0.25 w t \% R_{3} R\end{array}$ & $\begin{array}{c}\phi P O P G=0.4+ \\
0.25 w t \% A_{3} R\end{array}$ & $\begin{array}{c}\phi P O P G=0.2+ \\
0.25 w \% R_{3} R\end{array}$ & $\phi P O P G=0$ \\
\hline $\begin{array}{l}d[\AA]] \\
\text { ratio } \\
\left.d_{A}[\AA]\right]\end{array}$ & $\begin{array}{c}70.9: 35.6 \\
1: 2 \\
70.9\end{array}$ & $\begin{array}{c}71.4: 37.8: 24 \\
1: 1.8: 3 \\
71.4\end{array}$ & $\begin{array}{c}71.7: 35.9: 24.1: 17.9 \\
1: 2: 3: 4 \\
71.7\end{array}$ & $\begin{array}{c}71.9: 36.6: 24.1: 18.1 \\
1: 2: 3: 4 \\
71.9\end{array}$ & $\begin{array}{c}72.9: 36.6 \\
1: 2 \\
72.9\end{array}$ & $\begin{array}{l}- \\
-- \\
--\end{array}$ \\
\hline $\begin{array}{l}d[\AA] \\
\text { ratio } \\
d_{B}[\AA]\end{array}$ & $\begin{array}{c}59.3: 29.8: 19.8 \\
1: 2: 3 \\
59.3 \\
\end{array}$ & $\begin{array}{c}60.6: 30.3: 20.2 \\
1: 2: 3 \\
60.6 \\
\end{array}$ & $\begin{array}{c}61.2: 30.5: 20.3 \\
1: 2: 3 \\
61.2 \\
\end{array}$ & $\begin{array}{c}62.2: 30.9: 18.1 \\
1: 2: 3 \\
62.2 \\
\end{array}$ & $\begin{array}{c}63.7: 31.9 \\
1: 2 \\
63.7 \\
\end{array}$ & $\begin{array}{c}61.6: 30.9: 20.6 \\
1: 2: 3 \\
61.6 \\
\end{array}$ \\
\hline
\end{tabular}

Table 2. Information from cryo-TEM images (representative examples Figures S3-S8): vesicles types indicated as (i), (ii) or (iii), according to Figure 3, and repeat bilayer distance $d_{\text {cryo. }}$

\begin{tabular}{|c|c|c|c|c|c|c|c|}
\hline$w t \% R_{A_{3} R}^{\phi P O P G}$ & & 1 & 0.6 & 0.5 & 0.4 & 0.2 & 0 \\
\hline 0.08 & $\begin{array}{c}\text { Vesicle type } \\
d_{\text {cryo }[\AA \AA}[\AA]\end{array}$ & $\begin{array}{l}\text { (i) } \\
--\end{array}$ & (i), (ii) & $\begin{array}{l}\text { (i), (ii), (iii) } \\
63.4 \pm 12.8\end{array}$ & $\begin{array}{l}\text { (i), (ii), (iii) } \\
73.4 \pm 17.6\end{array}$ & $\begin{array}{c}\text { (i), (ii) } \\
57.9 \pm 8.2\end{array}$ & $\begin{array}{c}\text { (i), (ii), (iii) } \\
64.8 \pm 4.1\end{array}$ \\
\hline 0.25 & $\begin{array}{c}\text { Vesicle type } \\
d_{\text {cryo }}[\AA]\end{array}$ & (i), (ii) & $\begin{array}{l}\text { (i), (ii), (iii) } \\
63.1 \pm 12.3\end{array}$ & (i), (ii), (iii) & $\begin{array}{c}\text { (i), (iii) } \\
64.3 \pm 11.1\end{array}$ & (i), (ii), (iii) & (i), (iii) \\
\hline 0.5 & $\begin{array}{c}\text { Vesicle type } \\
d_{\text {cryo }}[\AA]\end{array}$ & $\begin{array}{l}-- \\
--\end{array}$ & $\begin{array}{l}- \\
--\end{array}$ & $\begin{array}{c}\text { (i), (ii) } \\
--\end{array}$ & $\begin{array}{l}- \\
--\end{array}$ & $\begin{array}{c}\text { (i), (ii), (iii) } \\
52.9 \pm 7.2\end{array}$ & $\begin{array}{c}\text { (i), (iii) } \\
69 \pm 10.5\end{array}$ \\
\hline
\end{tabular}




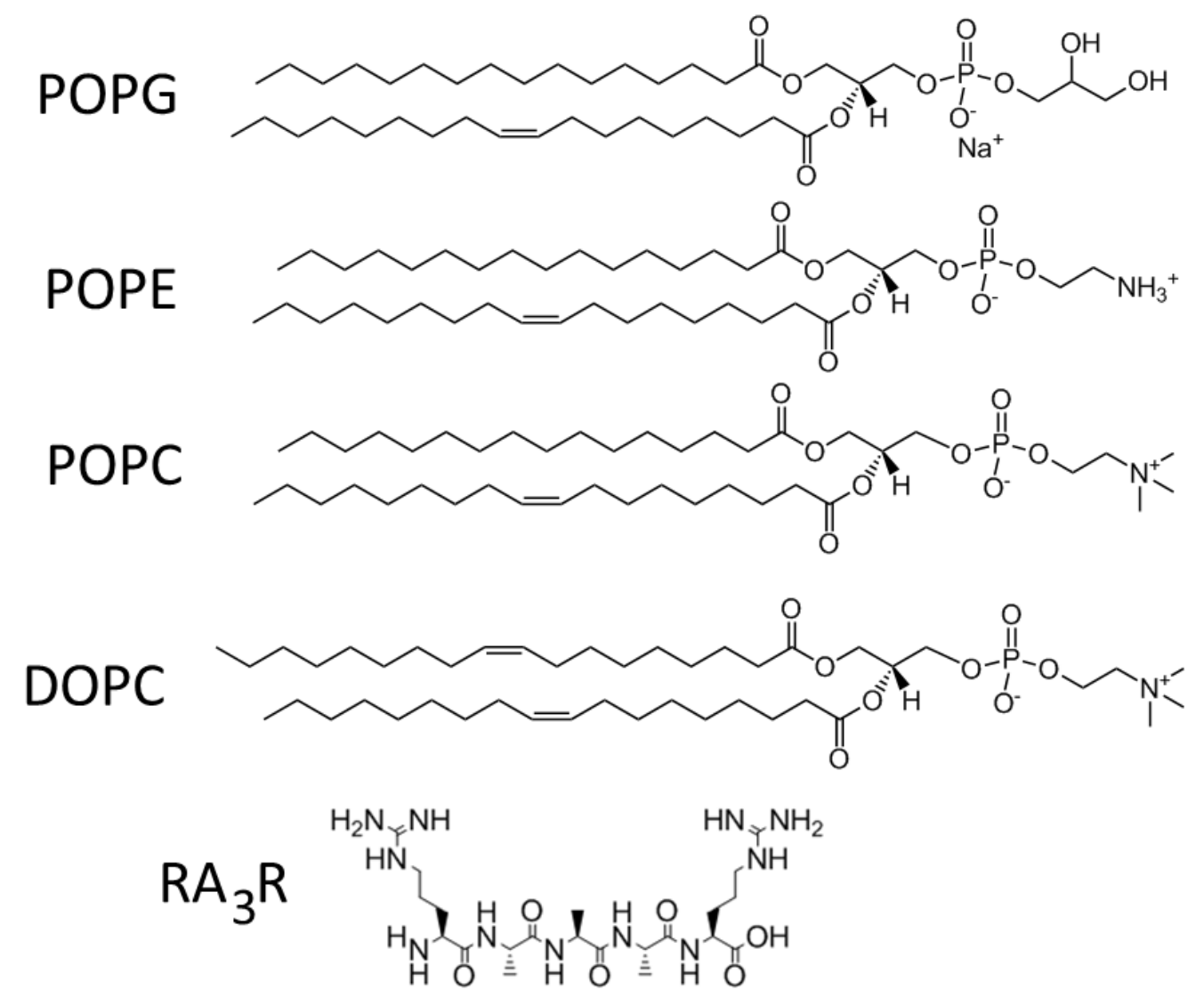

Scheme 1. Chemical formulas for the lipids and peptide used in this work 

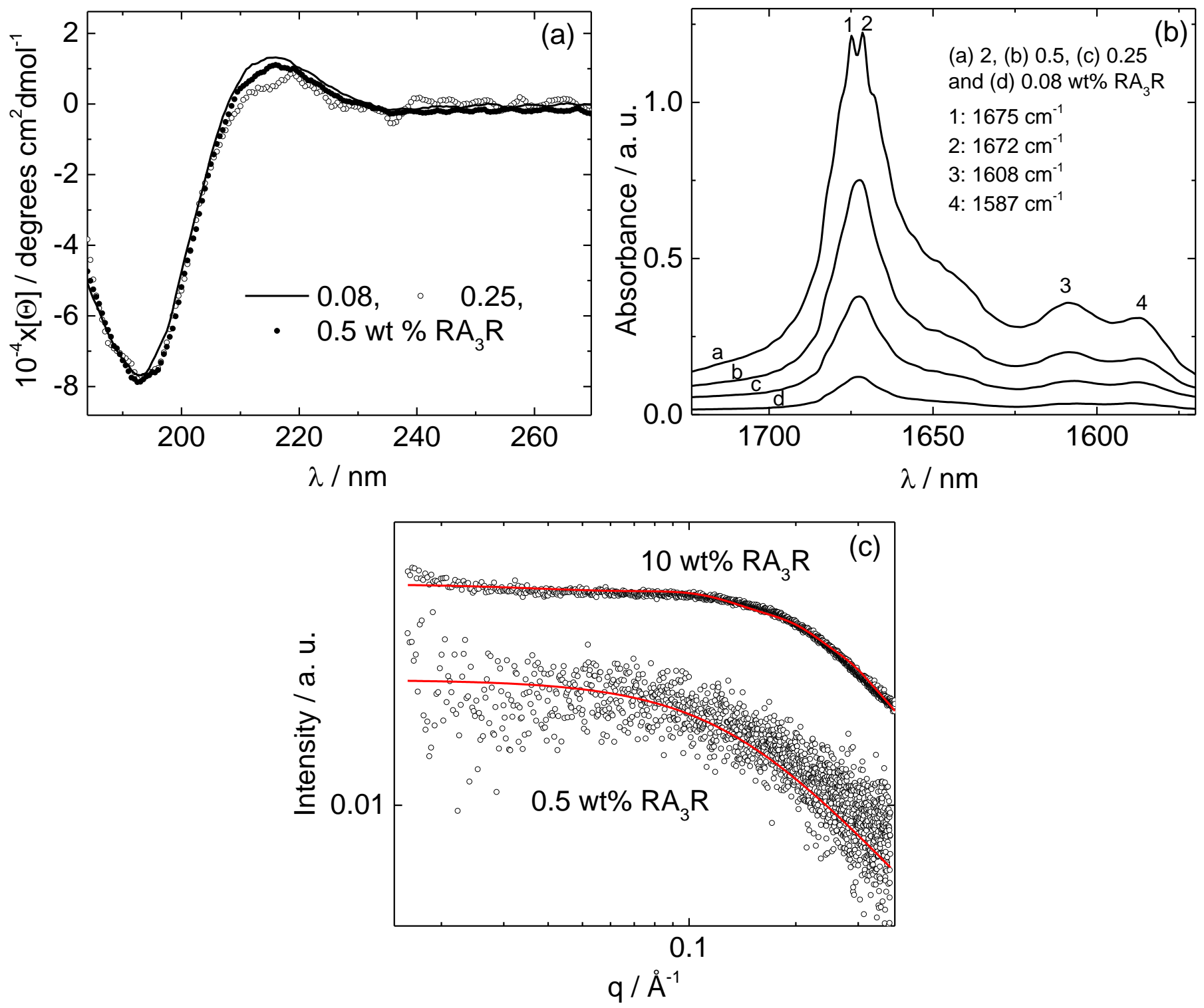

Figure 1. (a) CD, (b) FTIR, (c) SAXS data for $R A_{3} R$ solutions. The full line in (c) corresponds to the fitting of the experimental data. The intensity of the FTIR spectra for $2 \mathrm{wt} \% \mathrm{RA} \mathrm{A}_{3} \mathrm{R}$ has been divided by 2 , and the SAXS data for $0.5 \mathrm{wt} \%$ has been multiplied by an arbitrary factor in order to aid visualisation. 

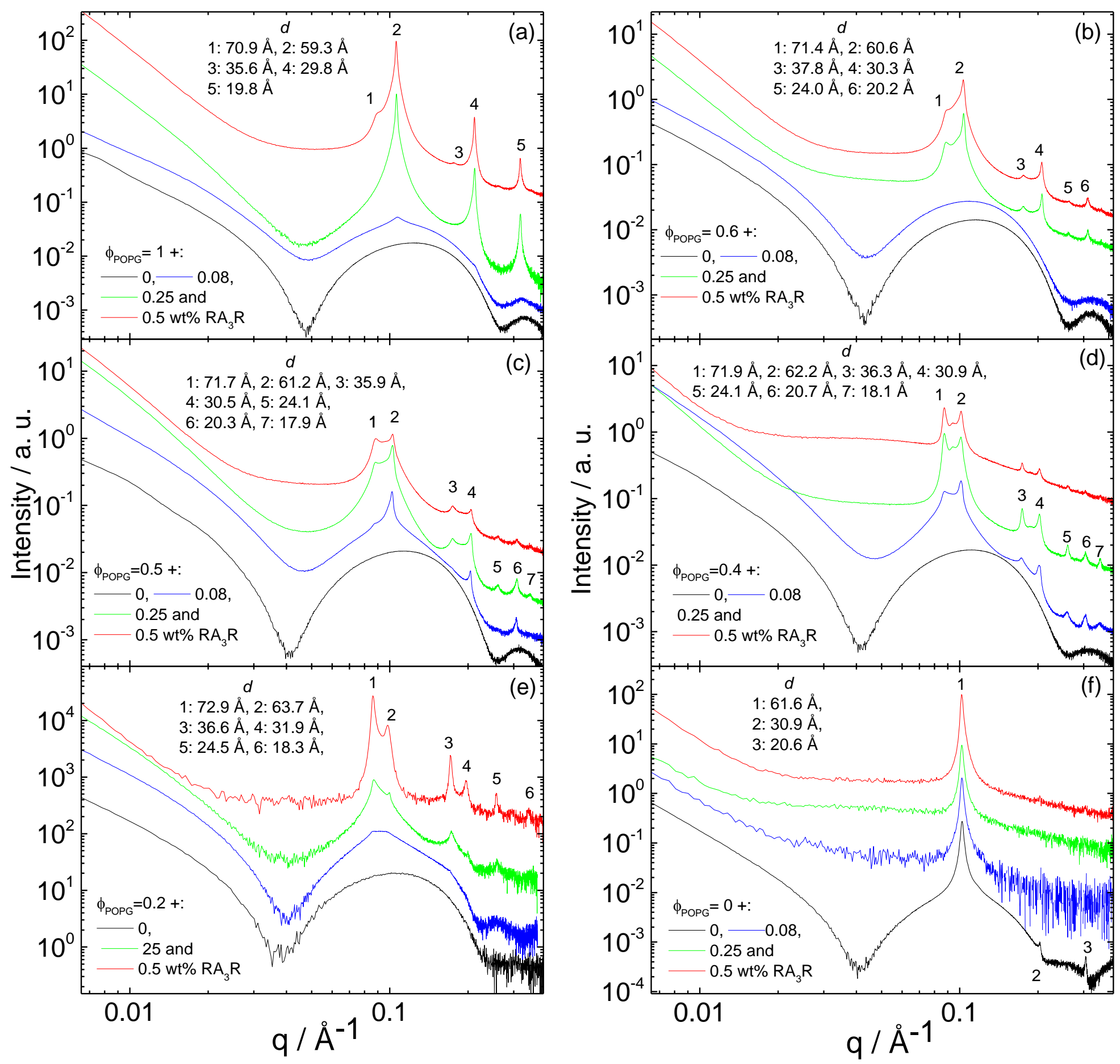

Figure 2. SAXS data for samples displayed in Table S1. The SAXS curves have been multiplied by an arbitrary factor in order to aid visualisation. Spacings $d=2 \pi / q_{0}$ ( $q_{0}$ : position of the peak maximum) were calculated using the reflexions indicated as 1-7. 

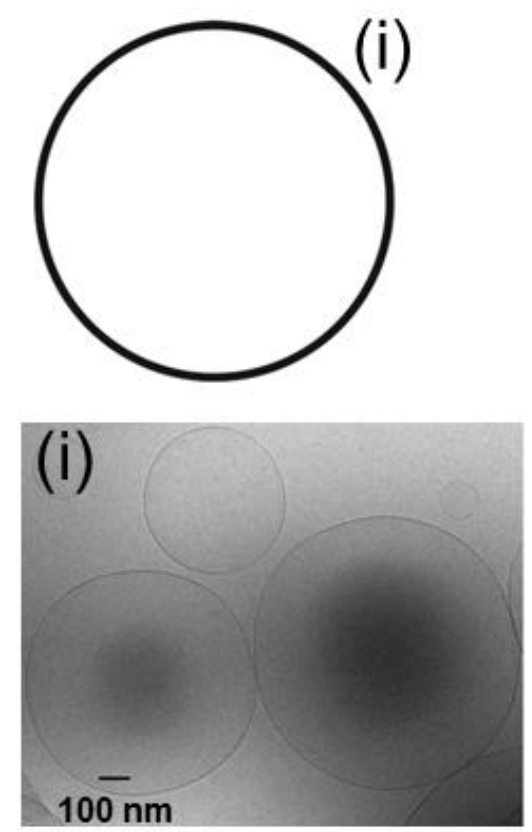
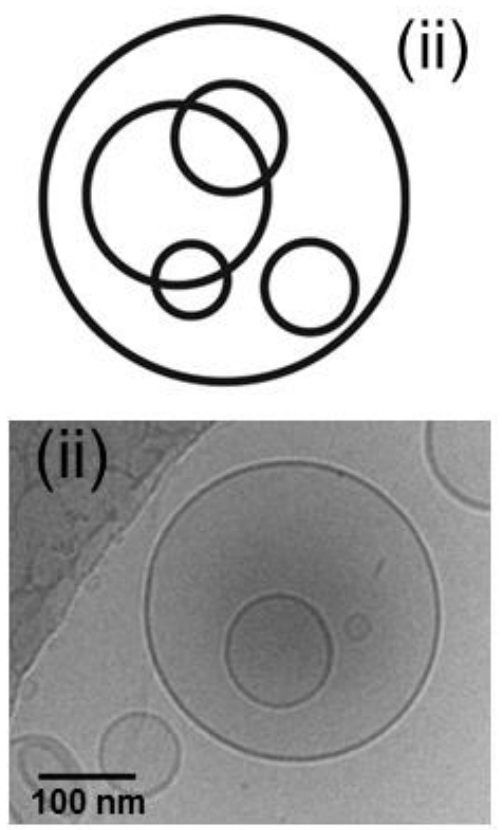
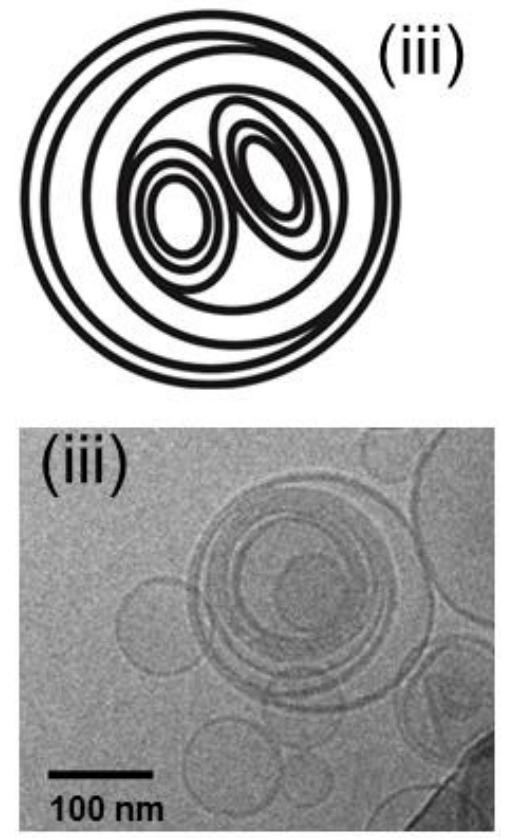

Figure 3. Classification of vesicle types. Top row: (i) Thin wall vesicles with no internal structure, (ii) Compartmentalized thin wall vesicles, (iii), multilayer vesicles with uncorrelated layers and compartmentalization. Bottom row: Typical cryo-TEM images for the three types (i) $\phi P O P G=0.2+0.08 w t \% R A_{3} R$ (ii) $\phi_{P O P G}=0.6+0.08 w t \% R A_{3} R$, (iii) $\phi P O P G=0.2+0.5 w t \%$ $\mathrm{RA}_{3} \mathrm{R}$. 


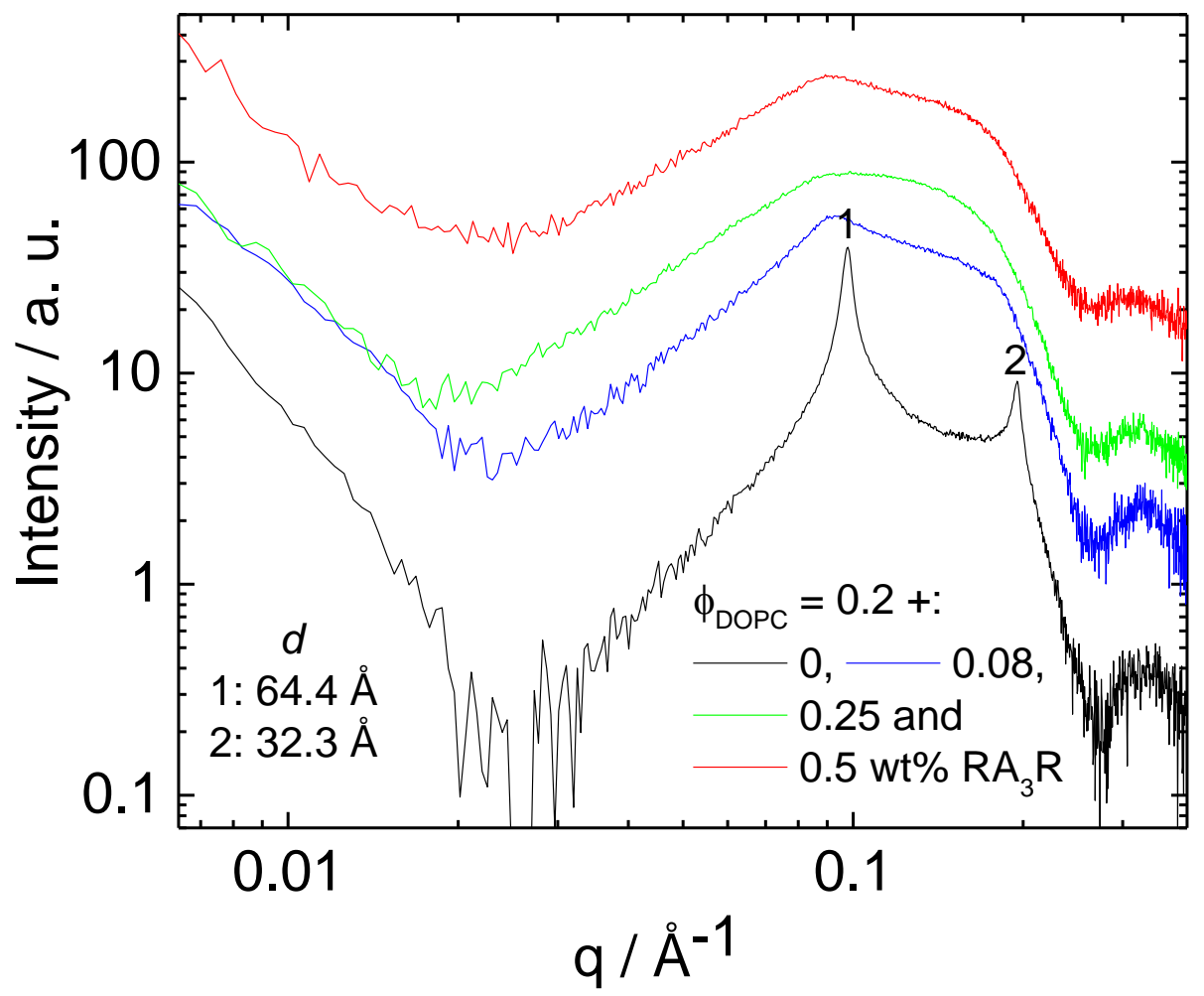

Figure 4. SAXS results obtained for samples with $\phi_{\mathrm{DOPC}}=0.2+0.08,0.25$ or 0.5 wt $\% R A_{3} R$. The SAXS curves have been multiplied by an arbitrary factor in order to aid visualisation. Spacings $d=2 \pi / q_{0}$ ( $q_{0}$ : position of the peak maximum) were calculated using the reflexions indicated as 1-2. 


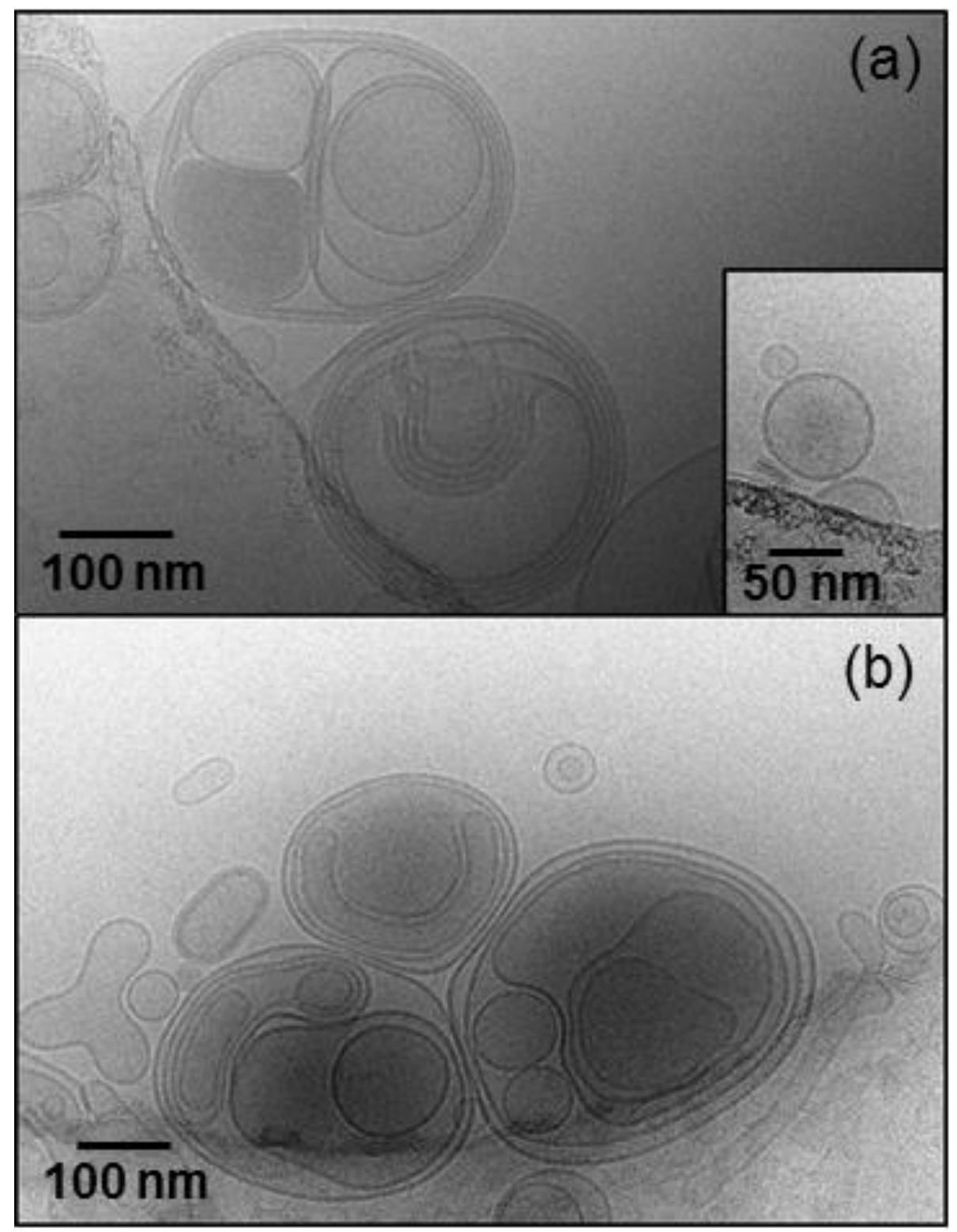

Figure 5. Cryo-TEM images recorded for $\phi_{\mathrm{DOPC}}=0.2+(\mathrm{a}) 0$ or (b) $0.5 \mathrm{wt} \% \mathrm{RA}_{3} \mathrm{R}$. 


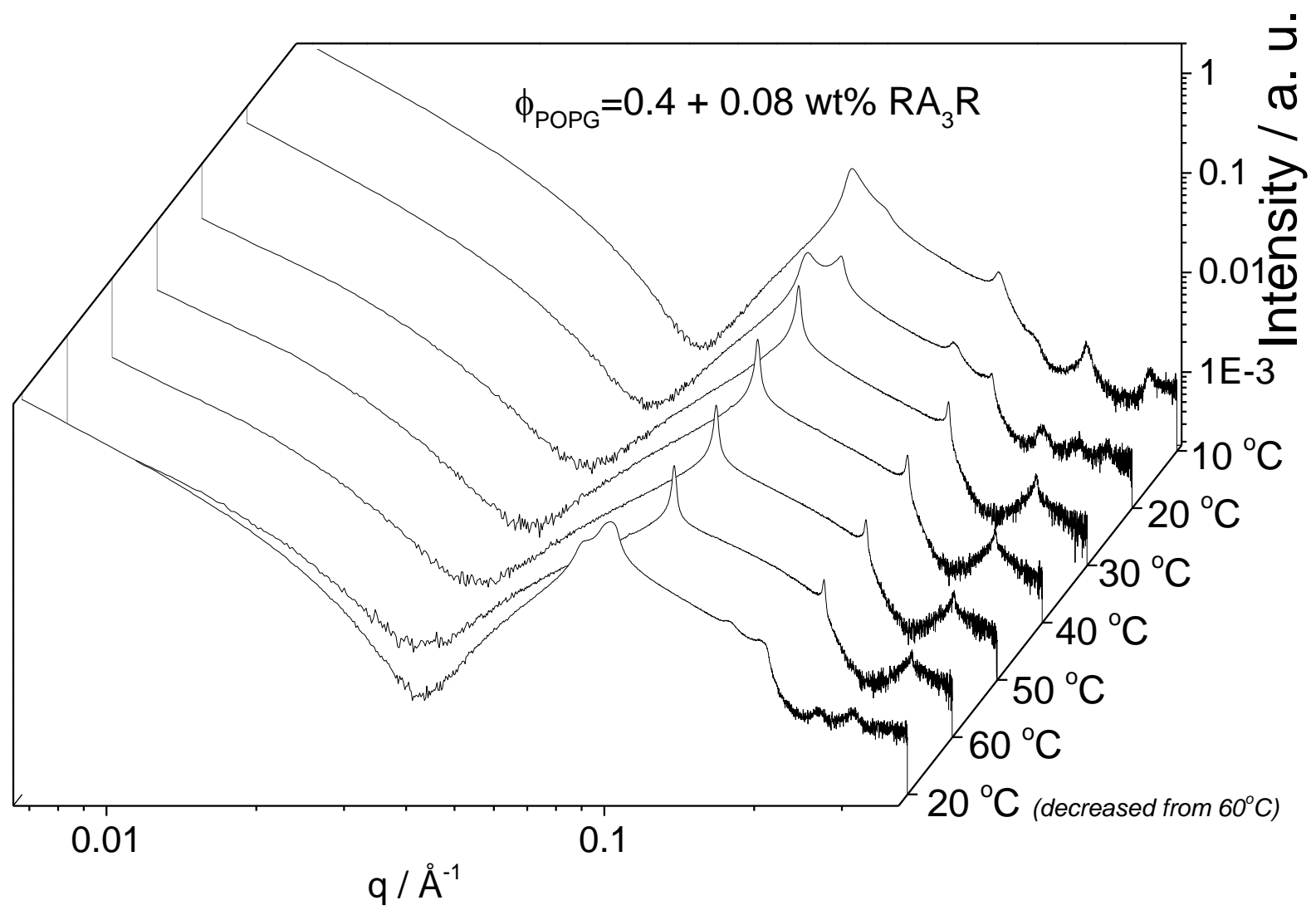

Figure 6. SAXS intensity profiles obtained for $\phi_{\mathrm{POPG}}=0.4+0.08 \mathrm{wt} \% \mathrm{RA} \mathrm{A}_{3} \mathrm{R}$, display the temperature dependence of the reflexions in Figure $2 \mathrm{~d}$. 


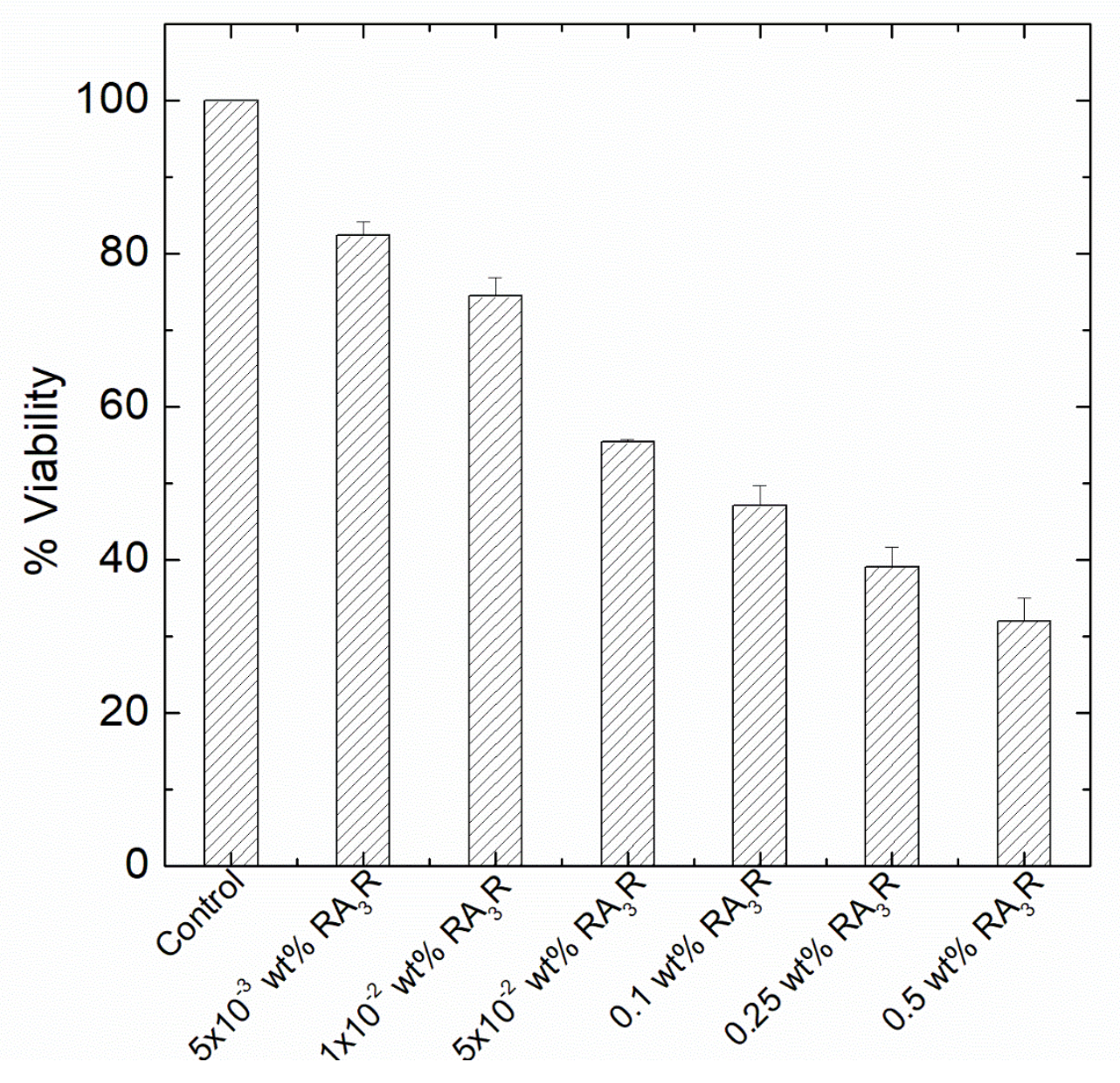

Figure 7. Cell viability of $\mathrm{RA}_{3} \mathrm{R}$ solutions. Error bars: $\mathrm{SEM}(n=3)$. All concentrations show statistical significance from the mean, $p<0.001$. 

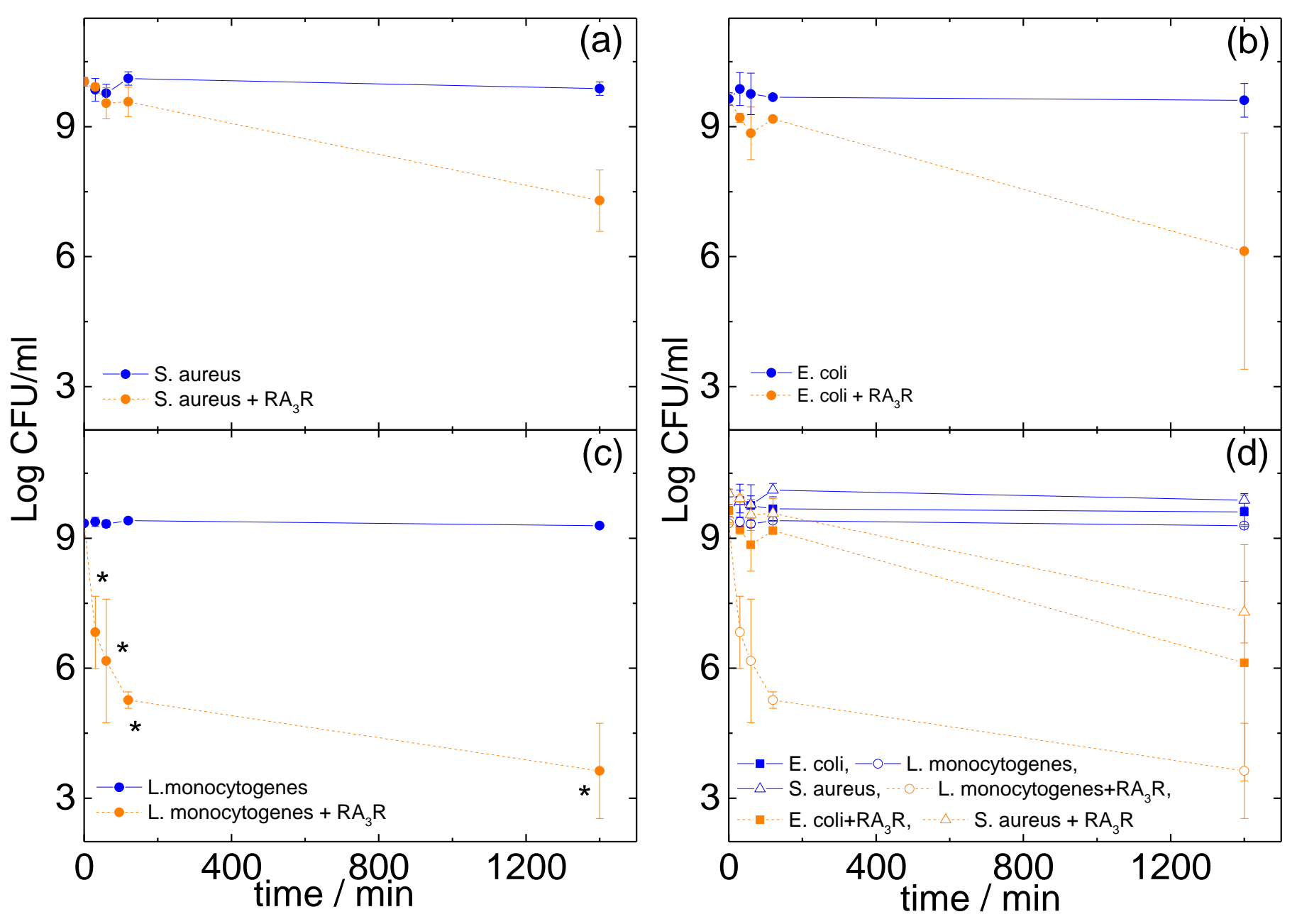

Figure 8. Survival of (a) S. aureus, (b) E. coli, and (c) L. monocytogenes after exposure to the presence (orange dash lines) or absence of $0.25 \mathrm{wt} \% \mathrm{RA} \mathrm{A}_{3} \mathrm{R}$ under aqueous conditions (blue full lines). (d) Data plotted in (a-c): E. coli (boxes), L. monocytogenes (circles), S. aureus (triangles). Estimations of the cell numbers (CFU: colony-forming units) at each time point were performed in triplicate ( 3 biological replicates) while each dilution was plated in duplicate (2 technical replicates). Markers represent an average of the measurements performed in triplicate, and error bars represent the standard deviation. Asterisks denote statistically significant difference between the treated and untreated strain at the specific time point as assessed by a t-test $(\mathrm{P}<0.05)$.

\section{References}


1. Vauthey, S.; Santoso, S.; Gong, H.; Watson, N.; Zhang, S., Molecular self-assembly of surfactant-like peptides to form nanotubes and nanovesicles. Proc. Nat. Acad. Sci USA 2002, 99, 5355-5360.

2. Santoso, S. S.; Vauthey, S.; Zhang, S., Structures, function and applications of amphiphilic peptides. Curr. Opin. Colloid Interface Sci. 2002, 7, 262-266.

3. von Maltzahn, G.; Vauthey, S.; Santoso, S.; Zhang, S. G., Positively charged surfactant-like peptides self-assemble into nanostructures Langmuir 2003, 19, 4332-4337.

4. Hauser, C. A. E.; Zhang, S. G., Designer self-assembling peptide nanofiber biological materials. Chem. Soc. Rev. 2010, 39, 2780-2790.

5. Castelletto, V.; Nutt, D. R.; Hamley , I. W.; Bucak, S.; Cenker, C.; Olsson, U., Structure of single-wall peptide nanotubes: In situ flow aligning X-ray diffraction. Chem. Comm. 2010, 46, 62706272.

6. Madine, J.; Castelletto, V.; Hamley , I. W.; Middleton, D. A., New insights into the molecular architecture of a peptide nanotube using FTIR and solid-state NMR combined with sample alignment Angew. Chem. 2013, 52, 10537-10540.

7. Castelletto, V.; Hamley, I. W.; Segarra-Maset, M. D.; Gumbau, C. B.; Miravet, J. F.; Escuder, B.; Seitsonen, J.; Ruokolainen, J., Tuning Chelation by the Surfactant-Like Peptide A(6)H Using Predetermined pH Values. Biomacromolecules 2014, 15, 591-598.

8. Hamley , I. W.; Dehsorkhi, A.; Castelletto, V., Self-Assembled Arginine-Coated Peptide Nanosheets in Water. Chem. Comm. 2013, 49, 1850-1852.

9. $\quad$ Castelletto, V.; Gouveia, R. J.; Connon, C. J.; Hamley, I. W.; Seitsonen, J.; Nykänen, A.; Ruokolainen, J., Alanine-rich amphiphilic peptide containing the RGD cell adhesion motif: a coating material for human fibroblast attachment and culture. Biomater. Sci. 2014, 2, 362-369.

10. Hamley, I. W.; Hutchinson, J.; Kirkham, S.; Castelletto, V.; Kaur, A.; Reza, M.; Ruokolainen, J., Nanosheet Formation by an Anionic Surfactant-like Peptide and Modulation of Self-Assembly through lonic Complexation. Langmuir 2016, 32, 10387-10393.

11. Cenker, C.; Bucak, S.; Olsson, U., Nanotubes and bilayers in a model peptide system. Soft Matter 2011, 7, 4868-4875.

12. Wang, X. Q.; Corin, K.; Baaske, P.; Wienken, C. J.; Jerabek-Willemsen, M.; Duhr, S.; Braun, D.; Zhang, S. G., Peptide surfactants for cell-free production of functional $\mathrm{G}$ protein-coupled receptors. Proc. Nat. Acad. Sci USA 2011, 108, 9049-9054.

13. Fatouros, D. G.; Lamprou, D. A.; Urquhart, A. J.; Yannopoulos, S. N.; Vizirianakis, I. S.; Zhang, S. G.; Koutsopoulos, S., Lipid-like Self-Assembling Peptide Nanovesicles for Drug Delivery. ACS Appl. Mater. Interfaces 2014, 6, 8184-8189.

14. Nagai, A.; Nagai, Y.; Qu, H. J.; Zhang, S. G., Dynamic behaviors of lipid-like self-assembling peptide A(6)D and A(6)K nanotubes. J. Nanosci. Nanotechnol. 2007, 7 , 2246-2252.

15. Chen, C. X.; Pan, F.; Zhang, S. Z.; Hu, J.; Cao, M. W.; Wang, J.; Xu, H.; Zhao, X. B.; Lu, J. R., Antibacterial Activities of Short Designer Peptides: a Link between Propensity for Nanostructuring and Capacity for Membrane Destabilization Biomacromolecules 2010, 11, 402-411.

16. Dehsorkhi, A.; Castelletto, V.; Hamley, I. W.; Seitsonen, J.; Ruokolainen, J., Interaction between a Cationic Surfactant-like Peptide and Lipid Vesicles and Its Relationship to Antimicrobial Activity. Langmuir 2013, 29, 14246-14253.

17. Zhao, Y.; Deng, L.; Yang, W.; Wang, D.; Pambou, E.; Lu, Z.; Li, Z.; Wang, J.; King, S.; Rogers, S.; $\mathrm{Xu}, \mathrm{H} . ;$ Varying the Hydrophilic Amino Acids. Chemistry-A European Journal 2016, 22, 11394-11404. 18. Zhao, Y. R.; Wang, J. Q.; Deng, L.; Zhou, P.; Wang, S. J.; Wang, Y. T.; Xu, H.; Lu, J. R., Tuning the Self-Assembly of Short Peptides via Sequence Variations. Langmuir 2013, 29, 13457-13464. 19. da Silva, E. R.; Walter, M. N. M.; Reza, M.; Castelletto, V.; Ruokolainen, J.; Connon, C. J.; Alves, W. A.; Hamley, I. W., Self-Assembled Arginine-Capped Peptide Bolaamphiphile Nanosheets for Cell Culture and Controlled Wettability Surfaces. Biomacromolecules 2015, 16, 3180-3190. 
20. Dowhan, W., Molecular basis for membrane phospholipid diversity: Why are there so many lipids? In Annual Review of Biochemistry, Richardson, C. C., Ed. Annual Reviews Inc. (California, USA): 1997; Vol. 66, pp 199-232.

21. Tattrie, N. H.; Bennett, J. R.; Cyr, R., Maximum and minimum values for lecithin classes from various biological sources. Canadian journal of biochemistry 1968, 46, 819-24.

22. Pozo Navas, B.; Lohner, K.; Deutsch, G.; Sevcsik, E.; Riske, K. A.; Dimova, R.; Garidel, P.; Pabst, G., Composition dependence of vesicle morphology and mixing properties in a bacterial model membrane system. BBA 2005, 1716, 40-8.

23. Karatzas, K. A. G.; Zervos, A.; Tassou, C. C.; Mallidis, C. G.; Humphrey, T. J., Piezotolerant small-colony variants with increased thermotolerance, antibiotic susceptibility, and low invasiveness in a clonal Staphylococcus aureus population. Appl. Environ. Microbiol. 2007, 73, 1873-1881.

24. Cotter, P. D.; O'Reilly, K.; Hill, C., Role of the glutamate decarboxylase acid resistance system in the survival of Listeria monocytogenes LO28 in low pH foods. J. Food Prot. 2001, 64, 1362-1368.

25. Begley, M. I.; Gahan, C. G. M.; Hill, C., Bile Stress Response in Listeria monocytogenes LO28: Adaptation, Cross-Protection, and Identification of Genetic Loci Involved in Bile Resistance. Appl. Environ. Microbiol.. 2002, 68, 6005-6012.

26. Bochicchio, B.; Tamburro, A. M., Polyproline II structure in proteins: Identification by chiroptical spectroscopies, stability, and functions. Chirality 2002, 14, 782-792.

27. Schweitzer-Stenner, R.; Measey, T.; Hagarman, A.; Eker, F.; Griebenow, K., Salmon calcitonin and amyloid $\beta$ : Two peptides with amyloidogenic capacity adopt different conformational manifolds in their unfolded states. Biochemistry 2006, 45, 2810-2819.

28. Woody, R. W., Circular Dichroism. Methods in Enzymology 1995, 246, 34-71.

29. Shi, Z. S.; Woody, R. W.; Kallenbach, N. R., Is polyproline II a major backbone conformation in unfolded proteins? In Unfolded Proteins, Rose, G. D., Ed. Academic Press Inc: San Diego, 2002; Vol. 62, pp 163-240.

30. Paramonov, S. E.; Jun, H.-W.; Hartgerink, J. D., Self-assembly of peptide-amphiphile nanofibers: The roles of hydrogen bonding and amphiphilic packing. J. Am. Chem. Soc. 2006, 128, 7291-7298.

31. Woody, R. W., Circular Dichroism Spectrum of Peptides in the Poly(Pro)II Conformation. J. Am. Chem. Soc. 2009, 131, 8234-8245.

32. Chen, K.; Liu, Z. G.; Kallenbach, N. R., The polyproline II conformation in short alanine peptides is noncooperative. Proc. Nat. Acad. Sci USA 2004, 101, 15352-15357.

33. Toniolo, C.; Formaggio, F.; Woody, R. W., Electronic Circular Dichroism of Peptides. In Comprehensive Chirooptical Spectroscopy, Berova, N.; Polavarapu, P. L.; Nakanishi, K.; Woody, R. W., Eds. New York, 2012; Vol. 2.

34. Drake, A. F.; Siligardi, G.; Gibbons, W. A., Reassesment of the electronic circular dichroism criteria for random coil conformations of poly(L-Lysine) and the implications for protein folding and denaturation studies. Biophys. Chem. 1988, 31, 143-146.

35. Pelton, J. T.; McLean, K. R., Spectroscopic methods for analysis of protein secondary structure Anal. Biochem. 2000, 277, 167-176.

36. Gaussier, H.; Morency, H.; Lavoie, M. C.; Subirade, M., Replacement of trifluoroacetic acid with $\mathrm{HCl}$ in the hydrophobic purification steps of pediocin PA-1: A structural effect Appl. Environ. Microbiol. 2002, 68, 4803-4808.

37. Eker, F.; Griebenow, K.; Schweitzer-Stenner, R., A beta(1-28) fragment of the amyloid peptide predominantly adopts a polyproline II conformation in an acidic solution. Biochemistry 2004, 43, 6893-6898.

38. Ghosh, A.; Tucker, M. J.; Hochstrasser, R. M., Identification of Arginine Residues in Peptides by 2D-IR Echo Spectroscopy. J. Phys. Chem. A 2011, 115, 9731-9738.

39. Barth, A., The infrared absorption of amino acid side chains. Progr. Biophys. Mol. Biol. 2000, 74, 141-173. 
40. Eker, F.; Cao, X. L.; Nafie, L.; Huang, Q.; Schweitzer-Stenner, R., The structure of alanine based tripeptides in water and dimethyl sulfoxide probed by vibrational Spectroscopy. J. Phys. Chem.

B 2003, 107, 358-365.

41. Schweitzer-Stenner, R., Dihedral angles of tripeptides in solution directly determined by polarized Raman and FTIR spectroscopy. Biophys. J. 2002, 83, 523-532.

42. Breßler, I.; Kohlbrecher, J.; Thünemann, A. F., SASfit: a tool for small-angle scattering data analysis using a library of analytical expressions. J. Appl. Cryst. 2015, 48, 1587-1598.

43. Kohlbrecher, J.; Bressler, I., Software package SASfit for fitting small-angle scattering curves. 2011.

44. Pabst, G.; Rappolt, M.; Amenitsch, H.; Laggner, P., Structural Information from Multilamellar Liposomes at Full Hydration: Full q-Range Fitting with High Quality X-Ray Data. Phys. Rev. E 2000, 62, 4000-4008.

45. Frampton, M. B.; Marquardt, D.; Letofsky-Papst, I.; Pabst, G.; Zelisko, P. M., Analysis of Trisiloxane Phosphocholine Bilayers. Langmuir 2017, 33, 4948-4953.

46. Sanver, D.; Murray, B. S.; Sadeghpour, A.; Rappolt, M.; Nelson, A. L., Experimental Modeling of Flavonoid-Biomembrane Interactions. Langmuir 2016, 32 (49), 13234-13243.

47. Nagle, J. F.; Tristram-Nagle, S., Structure of lipid bilayers. BBA-Biomembranes 2000, 1469, 159-195.

48. Manges, A. R., Escherichia coli and urinary tract infections: the role of poultry-meat. Clin. Microbiol. Infect. 2016, 22, 122-129.

49. Paudyal, R.; Barnes, R. H.; Karatzas, K. A. G., A novel approach in acidic disinfection through inhibition of acid resistance mechanisms; Maleic acid-mediated inhibition of glutamate decarboxylase activity enhances acid sensitivity of Listeria monocytogenes. Food Microb. 2018, 69, 96-104.

50. Ghosh, B. K.; Carroll, K. K., Isolation, composition, and structure of membrane of Listeria monocytogenes. J. Bact. 1968, 95, 688-99. 


\section{Table of Contents picture}

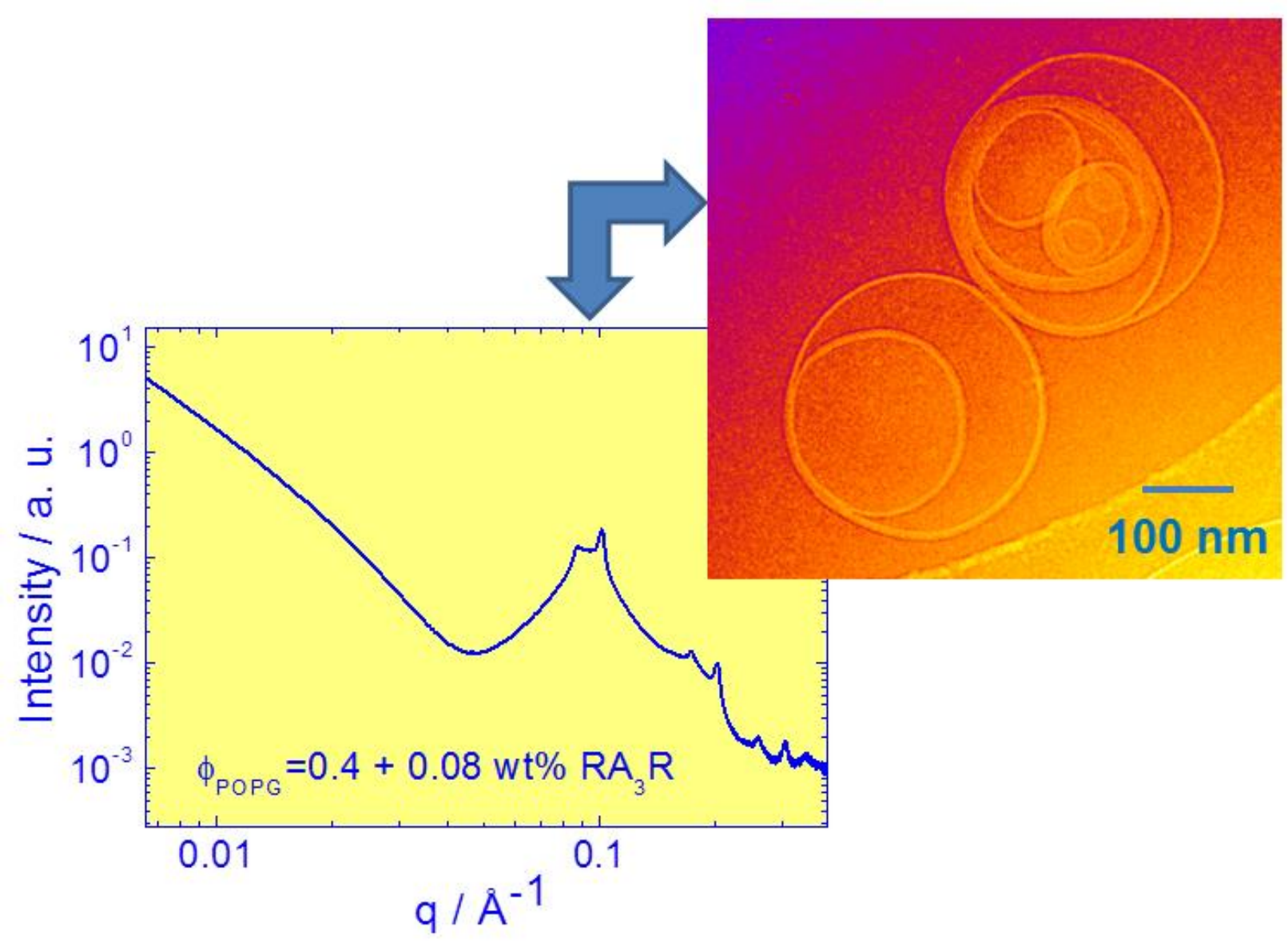

Addition of $\mathrm{RA}_{3} \mathrm{R}$ bolaamphiphile restructures the lipid bilayers of anionic vesicles 